\title{
O ENSINO TÉCNICO-PROFISSIONALIZANTE NO PARANÁ NA DÉCADA DE 1960
}

\section{The Vocational Technical Teaching in Paraná in the Decade of 1960}

Vanessa Melo do Nascimento ${ }^{1}$

Maria Elisabeth Blanck Miguel ${ }^{2}$

\section{Resumo}

O texto apresenta alguns dos principais aspectos da educação profissionalizante no Estado do Paraná na década de 1960, dentre eles: escolas, cursos ofertados e demanda. No período, a educação profissional paranaense estava começando a desenvolver-se, muitas das características apresentadas no Estado estavam em consonância com a política nacional de educação. No entanto, alguns dos cursos não estavam em concordância com as necessidades do mercado de trabalho, porém eram estruturados em função das condições existentes nas escolas. Os mais procurados eram aqueles relacionados ao Comércio. Os dados apresentados no texto, em sua maioria, são frutos de fontes primárias.

Palavras-chave: Educação profissionalizante; Paraná; 1960.

\section{Abstract}

The text introduces some of the principal aspects of the vocational education in the State of Paraná in the decade of 1960, such as: schools, courses presented in the period and the demand for each of them. In the period the paranaense professional education was beginning to grow, many of the characteristics presented in the State were in consonance with the national politics of education. However, some of the courses were not in consonance with the needs of the job market, they were structured in function of the conditions existent in the schools. In the period the most sought courses were those related to the Trade. The data presented in the text, is in its majority fruits of primary sources.

Keywords: Vocational education; Paraná; 1960.

1 Mestranda do programa de Pós-Graduação - Mestrado em Educação da Pontifícia Universidade Católica do Paraná. vanessamelo28@yahoo.com.br

2 Professora Doutora em História e Filosofia da Educação do Programa de Pós-Graduação em Educação da Pontifícia Universidade Católica do Paraná. maria.elisabeth@pucpr.br 


\section{Ensino Técnico-Profissionalizante no Paraná na década de 1960}

Durante a década de 1960, a economia paranaense era ainda essencialmente agrícola. O estado crescia em termos demográficos e estava se tornando um dos mais populosos do país. Para Wachowicz (2001, p. 279), “A partir da década de 1960, o Paraná pode ser considerado um estado territorialmente ocupado".

Conforme a Secretaria de Educação e Cultura, na década de 60, houve uma inadaptação entre o ensino propiciado pelas escolas e as necessidades de desenvolvimento do país e do estado:

A preparação adequada e diversificada dos jovens no ensino médio, para uma redistribuição da população de trabalho, deverá ser feita não só nas escolas de tipo acadêmico, quase sempre orientadas na preparação para ingresso em cursos superiores, mas em escolas que lhes dêem habilitação para o exercício de profissões de nível médio (SECRETARIA DE EDUCAÇÃO E CULTURA, 1962, p. 11).

Por essa razão, o governo estadual iniciou a construção de ginásios industriais; estes deveriam conter oficinas para a realização das aulas práticas na área industrial. Um dos relatórios apresentados pelo governador apontou que o ensino profissional no Paraná contava com apenas três escolas públicas e as demais instituições eram todas particulares.

Por determinação da Lei de Diretrizes e Bases da Educação Nacional n 4.024/61, as secretarias de educação e cultura deveriam reorganizar todos os estabelecimentos de ensino médio, a fim de propiciar formação profissional a seus freqüentadores. No estado do Paraná, no ano de 1962, a Secretaria de Educação e Cultura começou a distribuir instruções metodológicas e sugestões de programas para to das as disciplinas do ensino médio.

Apesar das instruções metodológicas, existiam ainda problemas de cunho administrativo, dentre eles: número insuficiente de funcionários, equipamentos em estado de funcionamento precário e falta de locais para o estabelecimento das escolas. Acrescente-se a esses dados a disparidade de renda per capita nas regiões paranaenses. Tais fatores afetaram a estruturação do ensino no Paraná, cabendo ao estado o custeio quase total da educação, fato que interferiu no desenvolvimento do ensino médio, pois este, em sua maioria, destinava-se à formação daqueles indivíduos que almejavam o ensino superior. Alguns municípios possuíam diferentes níveis de ensino médio, enquanto outros não contavam nem com uma unidade escolar dessa etapa de ensino. 
No ano de 1962, existiam no Paraná 404 estabelecimentos que ofertavam o ensino médio, destes 186 ofertavam o ensino secundário, 59 o ensino comercial, 2 o ensino industrial, 4 o ensino agrícola e 197 o ensino normal. Apesar destes números, o relatório apresentado no ano de 1965 apontou para a necessidade de investimentos em formação de mão-de-obra, já que o Brasil se desenvolvia e necessitava "cada vez mais de técnicos de nível médio qualificados a fazer funcionar este complexo industrial ávido de mão-de-obra capaz de movimentá-lo" (PARANÁ, 1965, p. 3). Devido a isso, o Paraná deveria ofertar mais cursos profissionalizantes para atender às necessidades mercadológicas que estavam se estruturando.

A Assembléia Legislativa do Estado decretou e sancionou a Lei $\mathrm{n}^{\circ}$ 4.978, de 5 de dezembro de 1964, que estabelecia as diretrizes e bases da educação no estado do Paraná. De acordo com a Companhia de Desenvolvimento Econômico do Paraná (CODEPAR), "Relativamente ao ensino comercial, industrial e agrícola, a legislação estadual segue as diretrizes gerais adotadas pelo sistema e pela legislação federal de ensino" (1966, p. 75). Ainda, segundo esse mesmo estudo, cabia ao Conselho Estadual de Educação formular as bases curriculares do ensino médio (incluindo o ensino técnico e profissional) para o estado, atendendo aos termos dispostos pela Lei $\mathrm{n}^{\circ} 4.024 / 61$.

Na mesma Lei $n^{\circ} 4.978(05 / 12 / 1964)$ foram citados os cursos de aprendizagem industrial e comercial, estes voltados para menores aprendizes que eram preparados para atuar em diferentes setores do comércio e da indústria. Vale ressaltar que por lei nacional, desde aquele período, as empresas deveriam ter menores aprendizes em seu quadro de funcionários. Tal diretriz foi estabelecida primeiramente pelo Decreto-Lei $\mathrm{n}^{\circ}$ 5.452, de $1^{\circ}$ de maio de 1943 , que aprovou a consolidação das Leis do Trabalho; após, a Lei n 10.097, de 19 de dezembro de 2000, que alterou os dispositivos da Consolidação das Leis de Trabalho e, por fim, pela Lei $n^{\circ} 11.180$, de 23 de setembro de 2005, que instituiu o Projeto Escola de Fábrica, autorizando a concessão de bolsas de permanência a estudantes beneficiários do Programa Universidade para Todos - PROUNI que instituiu o Programa de Educação Tutorial - PET, alterando a Lei número 5.537, de 21 de novembro de 1968, e a Consolidação das Leis do Trabalho - CLT, aprovada pelo Decreto-Lei número 5.452, de 1o de maio de 1943.

O estudo para a formação de técnicos de nível médio no estado fazia o seguinte apontamento:

Os estabelecimentos de ensino industrial podem manter, também, cursos de aprendizagem básicos ou técnicos bem como cursos de artesanato e de mestria. Até aqui, como educação formal, tais tipos de cursos têm sido ministrados no Paraná em escolas técnicas ou do SENAI.Os cursos de 
aprendizagem industrial e comercial, que as empresas industriais e comerciais são obrigadas a ministrar em cooperação, aos menores seus empregados, têm duração de 1 a 3 anos e dão direito aos que concluírem a matricular-se, mediante exame de habilitação, em ginásios de ensino técnico, em série adequada ao grau de estudo que hajam atingido (CODEPAR, 1966, P. 76).

No que confere ao ensino técnico e profissional, no capítulo II, seção II da Lei $\mathrm{n}^{\circ}$ 4.978, de 5 de dezembro de 1964, este deveria ser destinado à formação de técnicos de grau médio, sendo que o ensino técnico no estado englobava cursos das áreas: industrial, agrícola, comercial e politécnica. Nessa mesma lei foi abordado o ciclo colegial técnico no colégio industrial, no qual deveriam ser ministradas como disciplinas obrigatórias: português, matemática, história e ciências. Conforme o estudo para a formação de técnicos de nível médio no estado do Paraná (1966, p. 80), adotaram-se as disciplinas obrigatórias para todos os ramos e cursos (secundário, normal e técnico profissional). Para que não houvesse o desperdício de recursos, o início da formação era comum para todos os alunos e, somente após a conclusão de uma determinada carga horária, os discentes começariam a receber as formações específicas, de modo que o governo não desperdiçasse recursos com laboratórios, oficinas, professores, etc., já que alguns alunos desistiam da formação antes de adentrarem à parte profissionalizante.

Segundo a Codepar (1966, p. 128), o ensino técnico industrial era ministrado na Escola Técnica Federal do Paraná (em Curitiba), no Instituto Politécnico Estadual, no Ginásio Industrial Presidente Kennedy (em Ponta Grossa), pelo Serviço Nacional de Aprendizagem Industrial (SENAI), nas escolas mantidas pela Rede Viação Paraná - Santa Catarina e no Ginásio Industrial Presidente Getúlio Vargas (em Guairá). No período, conforme 0 relatório da Codepar (1966), a Escola Técnica Federal do Paraná foi considerada uma das melhores do Brasil, em termos de instalações e equipamentos.

No entanto, vale ressaltar que no ano de 1965 não se encontrava em fase de instalação nenhum colégio técnico ou instituto politécnico que fosse ministrar o ensino industrial no estado, apenas foi reivindicado pela população uma escola que ofertasse esse ensino na cidade de Londrina.

Os cursos ministrados pelo Instituto Politécnico o eram no período noturno, enquanto que os oferecidos na Escola Técnica eram diurnos. Isso fazia com que houvesse mais alunos matriculados no Instituto Politécnico, pois a maioria deles trabalhava durante 0 dia.

A formação de mão-de-obra mediante associações entre escola e empresa ainda era pouco utilizada. Na década de 60, as primeiras experiências que lograram êxito por meio dessas associações foram as ministradas pelo Serviço Nacional de Aprendizagem Industrial (SESI). 
Nessa mesma década, havia os seguintes cursos no Colégio Industrial: Desenho Técnico; Eletrônica; Eletrotécnica; Máquinas e Motores e Química. Tais cursos possuíam duração de três anos e incluíam a prática de estágio supervisionado.

No período compreendido entre 1960 e 1964, as matrículas no ensino industrial paranaense, conforme o Plano de Educação apresentado no ano de 1968, triplicaram, passando de 595 a 1808 alunos. Já no ano de 1965 houve 1.244 matrículas, sendo 196 em cursos técnicos, 955 no ginásio industrial e 93 no curso de aprendizagem industrial. Em Curitiba, o ensino industrial visava a formação de técnicos de nível médio para o trabalho na indústria. Essa etapa de ensino era ministrada em dois ciclos:

O primeiro ciclo, denominado ginásio industrial, procura ampliar a cultura geral dos jovens preparando-os para o prosseguimento dos estudos e, paralelamente, inicia-os, através de prática em oficinas, nas técnicas de atividades produtivas. É um curso básico de 4 anos de duração para menores acima de 11 anos de idade, egressos das escolas primárias. O segundo ciclo, colegial, com duração mínima de 3 anos, ministra diversos cursos e objetiva a formação de técnicas para o desempenho de funções de imediata assistência a engenheiros ou para exercerem profissões técnicas mais graduadas, possibilitando o acesso aos estudos em nível superior (PLANO DE EDUCAÇÃO, 1968, p. 63).

O ginásio industrial era proporcionado somente na Escola Técnica Federal do Paraná e o Colégio Industrial, ofertado pela Escola Técnica Federal ${ }^{3}$ e pelo Instituto Politécnico Estadual.

Segundo o Plano Estadual de Educação, no ano de 1966, foi pequeno o número de técnicos formados conforme constava no Plano de Educação de 1968:

(...) chegando-se a lamentar que certos cursos, com duração de 3 a 4 anos, funcionem só para formar 1 técnico, como é o caso do Curso de Decoração; diante das solicitações do mercado de trabalho, seria conveniente fazer uma divulgação mais ampla entre os alunos de $1^{\circ}$ ciclo para atrair maior número de candidatos (p. 66).

Nesse mesmo Plano foi apontado que muitos dos técnicos formados iriam ingressar no ensino superior devido à falta de valorização dos profissionais oriundos de formações técnicas.

3 De acordo com o Plano de Educação (1968, p. 67), a Escola Técnica Federal do Paraná mantinha duas modalidades de cursos: Cursos de Aprendizagem, para maiores de 14 anos de idade, com escolaridade primária completa e Cursos Técnicos Especiais, para jovens com 0 $2^{\circ}$ ciclo completo. Ambos os cursos tinham duração de 2 anos. 
Pelo quadro abaixo se pode observar o índice de evasão e o rendimento escolar dos cursos profissionalizantes, no ano de 1966:

\begin{tabular}{l|r|r|r|r|r}
\hline \multirow{2}{*}{ Curso } & \multicolumn{2}{|c|}{ Matrícula } & Aprovação & Evasão & $\begin{array}{c}\text { Ren dimento } \\
\text { Real }\end{array}$ \\
\cline { 2 - 5 } & Inicial & Efetiva & & & $17 \%$ \\
\hline Aprendizagem Industrial & 252 & 185 & 43 & $27 \%$ & $77 \%$ \\
Marcenaria & 48 & 42 & 37 & $12 \%$ & $50 \%$ \\
Composição Manual & 36 & 22 & 18 & $39 \%$ & $100 \%$ \\
Linotipia & 10 & 15 & 11 & & $88 \%$ \\
Impressão & 16 & 20 & 14 & & $100 \%$ \\
Encadernação & 10 & 14 & 11 & & $100 \%$ \\
Ajustagem & 8 & 9 & 9 & & $69 \%$ \\
Serralheria & 16 & 14 & 11 & $12 \%$ & $78 \%$ \\
Mecânica de Automóveis & 59 & 53 & 46 & $10 \%$ & $100 \%$ \\
Tornearia Mecânica & 15 & 15 & 15 & & $85 \%$ \\
Solda & 13 & 12 & 11 & $8 \%$ & $90 \%$ \\
Mecânica Geral & 119 & 116 & 108 & $3 \%$ & $78 \%$ \\
Eletricidade & 40 & 34 & 31 & $15 \%$ & $100 \%$ \\
Eletric. Locom. Diesel & 5 & 5 & 5 & & $100 \%$ \\
Mecânica Locom. Diesel & 11 & 11 & 11 & & $\mathbf{5 8 \%}$ \\
\hline Total & $\mathbf{6 5 8}$ & $\mathbf{5 6 7}$ & $\mathbf{3 8 1}$ & $\mathbf{1 4 \%}$ & \\
\hline
\end{tabular}

Fonte: Plano de Educação: 1968

Os dados apresentados no quadro acima evidenciam que a taxa mais elevada de evasão no ano de 1966 foi no curso de Composição Manual, seguido pelo de Aprendizagem Industrial. Não houve evasões nos cursos de Linotipia, Impressão, Encadernação, Ajustagem, Tornearia Mecânica, Eletric. Locom. Diesel e Mecânica Locom. Diesel.

No que diz respeito ao Colégio Agrícola, a Lei $\mathrm{n}^{\circ}$ 4.978/64 apontava para a obrigatoriedade da presença nos curnículos das disciplinas de Português, Matemática, Geografia e Ciências, cabendo ainda ao estabelecimento de ensino escolher, entre as disciplinas de História, Língua Estrangeira Moderna, Filosofia, Organização Social e Política Brasileira, Estudos Sociais e Desenho, uma delas para ser ministrada durante o transcorrer do curso. As disciplinas específicas do curso colegial agrícola eram: Agricultura, Desenho Técnico, Noções de Economia e Sociologia Rural, Noções de Veterinánia, Tecnologia Agrícola e Animal, Higiene Rural e Socorros de Urgência e Organização do Trabalho.

O Colégio Comercial contava com as disciplinas de Português, Matemática, História e Ciências, como sendo obrigatórias. Competia ao estabelecimento de ensino optar por uma dentre as disciplinas de Geografia, Língua 
Estrangeira Moderna, Ética, Organização Social e Política Brasileira, Estudos Sociais ou Desenho. A disciplina escolhida seria ministrada durante uma das três séries do curso. Na década de 1960 eram ofertados no Colégio Comercial os seguintes cursos: Contabilidade; Administração; Secretariado; Estatística e Comércio e Propaganda.

De acordo com a Codepar (1966, p. 96), até o final de 1965 o Paraná já contava com 82 estabelecimentos de ensino comercial, dos quais 58 eram mantidos pelo estado e 31 por instituições particulares. Estes dados comprovam que na década de 60, os cursos mais procurados pela população paranaense eram aqueles que tinham como fim a formação para o comércio. Tal fato também pode ser comprovado mediante os dados apresentados no Plano de Educação, principalmente quando este abordava a realidade da cidade de Curitiba:

...a hipótese de que Curitiba é uma cidade em que predominam as atividades terciárias, para cuja preparação de recursos humanos as entidades mantenedoras do Ensino Particular têm demonstrado apurada sensibilidade, com a multiplicação de escolas e cursos avulsos desse ramo (PLANO DE EDUCAÇÃO, 1968, p. 83).

No estado do Paraná, na década de 60, ainda existiam colégios técnicos que ofereciam cursos de Agrimensura, Edificações, Estradas e de Meteorologia. Estes deveriam ministrar obrigatoriamente as disciplinas de Português, Matemática, Geografia e Ciências e podiam optar por ofertar uma das seguintes disciplinas: História, Língua Estrangeira Moderna, Organização Social e Política Brasileira, Estudos Sociais e Desenho para ser ministrada no transcorrer do curso.

Ainda, na Lei $\mathrm{n}^{\circ}$ 4.978/64, foram dispostas as regulamentações para a Escola Normal de Grau Colegial, que também contava com disciplinas obrigatórias e específicas para desempenho da função docente.

Existia no estado um outro tipo de ensino técnico profissional ministrado em Institutos Politécnicos, mantido pelo poder público ou privado. Para propiciar a formação de técnicos de nível médio, no Paraná, tais Institutos deveriam reunir:

...mais de um curso em um único estabelecimento e destinam-se especificamente à formação de técnicos de nível médio de $2^{\circ}$ ciclo. Somente são admitidos à matrícula na $1^{\text {a }}$ série dos seus cursos os portadores de certificado de conclusão do $1^{\circ}$ ciclo, de qualquer curso de grau médio, que forem aprovados em concurso de habilitação. No Paraná funciona, atualmente, um único estabelecimento de ensino politécnico, o Instituto Politécnico Estadual, mantido pelo Governo do Estado, com sede em Curitiba (CODEPAR, 1966, p. 79). 
Conforme esse mesmo documento, todos os cursos que ofertavam formação profissional deveriam dar ênfase à área de Moral e Cívica e à Ética Profissional.

As informações disponíveis sobre a demanda de técnicos industriais no Estado durante o período são muito precárias. Existia, na década de 1960, uma carência no que se referia à formação de técnicos industriais no Estado do Paraná. Nos cursos mantidos pelo Instituto Politécnico Estadual e pela Escola Técnica, o número total de técnicos formados entre os anos de $1960 \mathrm{e}$ 1965 foi de 286, assim distribuídos: Agrimensura: 24; Decorações 17; Edificações: 28; Eletrônica: 12; Eletrotécnica: 38; Máquinas e Motores: 53; Meteorologia: 3; Pontes e Estradas: 21 e Química: 78.

A oferta de cursos implantados no estado delimitava-se pelas condições existentes nas escolas (ou instituições) e não era adequada à demanda do mercado, de modo que os cursos industriais, nesse período, foram implantados em função de equipamentos, instalações e corpo docente existente e não conforme as necessidades do mercado de trabalho. Havia, em alguns cursos, falta de alunos, utilização de equipamentos ultrapassados, insipiência na formação dos professores.

No relatório apresentado pela Codepar(1966), foi apontado que existia ainda no Paraná uma preferência pela escola secundária do tipo acadêmica, já que cerca de $70 \%$ do total de alunos matriculava-se nesse ramo de ensino.

Conforme dados constantes no Plano Básico de Educação, a formação profissional ofertada no estado, na década de 60, deixava a desejar no que se referia à qualidade de seus cursos, já que:

Ainda quando se visou a criação de ginásios e colégios orientados para um tipo dado de atividade produtiva, ou mesmo quando se discutiu a implantação de 'ginásios orientados para o trabalho', não se atentou devidamente para o fato de que o sistema como um todo, sem sofreruma reorientação pela base, não seria capaz de inserir os novos objetivos. Com exceção dos colégios comerciais, que poderiam oferecer uma formação profissional definida e amparada por regulamentação do exercício profissional, os cursos profissionalizantes de segundo ciclo, geralmente, acabavam por não dar satisfatoriamente, nem a formação cultural básica, nem a habilitação específica (PLANO BÁSICO DE EDUCAÇÃO, 1969, p. 3).

Entretanto, no mesmo plano, foi apontado que a complexidade do mercado de trabalho estava exigindo uma melhor preparação técnica dos indivíduos, o que se tornou um desafio para a escola média.

O encerramento das atividades educacionais no Paraná, no ano de 1969, deu-se conforme o Informativo do Governo Paulo Pimentel (1970), com a realização do I Simpósio de Ensino do Paraná (SENPAR): 
...o qual contou com a participação de mais de 6 mil pessoas, além de delegações da maioria dos Estados brasileiros e representantes de órgãos nacionais e de organismos internacionais ligados à educação, tais como USAID, BID. Neste Simpósio foram estabelecidas as recomendações preliminares para a montagem do Plano Estadual de Educação (INFORMATIVO, 1970, s/p.)

Tal Seminário, de acordo com Plano de Ação Cultural do Governo do Paraná (1973), teve o intuito de promover o diálogo entre diversos partícipes do processo educativo, cujo fim foi discutir sobre os problemas do ensino no Paraná, bem como estruturar um sistema mais aberto, voltado para o desenvolvimento econômico.

\title{
Considerações finais
}

Na década de 1960, o Paraná já estava despertando para o processo de industrialização e o poder público estadual começou a investir nas escolas que ofertavam cursos profissionalizantes, ainda que de maneira lenta. Os cursos mais procurados eram aqueles relacionados ao comércio, pois o processo de industrialização ainda estava em seu despertar.

Poucos são os estudos direcionados à história da educação profissional no Brasil. Para aqueles que atuam com essa etapa de ensino, o conhecimento de fontes históricas é imprescindível, para que se tornem conhecidos muitos de seus aspectos. Para uma educação profissional de qualidade, precisa-se compreender a gênese de seu processo, bem como o seu desenvolvimento, pois a partir deles poderão ser possíveis alternativas que sejam válidas e pertinentes às suas especificidades.

\section{Referências}

CODEPAR - Companhia de Desenvolvimento Econômico do Paraná. Estudo para a formação de técnicos de nível médio no Estado do Paraná. Janeiro de 1966. v. 1.

\begin{abstract}
DELIBERAÇÃO nº 012/77. Permite a redução da duração dos cursos de habilitações plenas relativas ao setor primário da Economia. Dispõe sobre o ajustamento curricular das 4as. dos cursos dessa natureza.
\end{abstract}

FUNDEPAR. Coletânea da legislação estadual de ensino: 1964-1967. Governador: Paulo Pimentel. 
GOVERNO do estado do Paraná. Alguns aspectos da situação educacional do Paraná nos últimos anos. Missão de planejamento do desenvolvimento econômico do estado do Paraná. PLADEP: 1965

GOVERNO Paulo Pimentel / Secretaria de Educação e Cultura / Administração Cândido Martins de Oliveira. Plano básico de educação (projeto) 19701975. Curitiba,1969.

Plano de Ação Cultural do Governo do Paraná. 2. ${ }^{\circ}$ SENPAR - Simpósio de ensino do Paraná. 1973

Plano de educação. Trabalho realizado pelo grupo de estudos de educação do instituto de pesquisa e planejamento urbano de Curitiba - IPPUC. Concluído em fevereiro de 1968. Governador: Paulo Cruz Pimentel: prefeito: Osmar Sabbag: Secretário de educação: Carlos Alberto Moro

Relatório apresentado ao Excelentíssimo Senhor Governador do Estado pelo Secretário de Educação e Cultura professor Vespero Mendes. Educação no Paraná 1964. 1964. Governador: General Ney Amintas de Barros Braga

Secretaria de Educação e Cultura. Capítulo da mensagem apresentada à Assembléia Legislativa do Estado pelo Governador Ney Aminthas de Barros Braga, no dia $1^{\circ}$ de maio de 1962

SECRETARIA da Educação e Cultura. Relatório de atividades / agosto de 1973 a julho de 1974. Governo Emílio Gomes.

SEEC, 1975. Regulamento da Secretaria de Estado da Educação e da Cultura. Lei n 6.636, 29/11/1974. Governador do Estado: Jayme Canet Junior / Secretario da Educação e da Cultura: Francisco Borsari Netto / Diretor Geral da Educação e da CULTURA: Ernesto Kanuer

WACHOWICZ, Ruy Christovam. História do Paraná. 9. ed. Curitiba: Imprensa Oficial do Paraná, 2001 